\title{
Reversible Cerebrovascular Syndrome
}

Mohammad Saadatnia, MD.

Professor of Neurology and Neuroradiology, Isfahan University of M edical Sciences, Iran.

Corresponding Author: Email: mosaadatnia@yahoo.com

Reversible cerebrovascular syndrome (RCVS) is clinico-radiological syndrome defined as severe recurrent thunderclap headache with or without seizures or neurologic deficits and constriction of cerebral arteries which resolves spontaneously within 1-3 months. RCVS affects patients in various racial and ethnic groups and in all age groups, although most commonly in the fourth decade of life. Headache is the main symptom. Headache is usually "thunderclap variety", peaks within one minute and very intense. M any conditions and exposures have been linked to RCVS, including vasoactive drugs, metabolic disorder, vasculitis and the peripartum period. Associated strokes and cerebral hemorrhages are not uncommon. As complications we can see Localized cortical SAH (20-25\%), Ischemic or hemorrhagic stroke (5-10\%), posterior reversible encephalopathic syndrome ( PRES). Permanent sequelae of RCVS is usually benign entity. Prognosis is highly dependent on the occurrence of stroke (6$9 \%$, otherwise, by definition, most resolve completely without any sequelae. Treatment is Symptomatic (pain, seizures, blood pressure control), trigger avoidance should be done (either activity or vasoactive substances), calcium channel blockers, IV magnesium and Short-course of steroids may be effective.

Key words: cerebrovascular syndrome

DOI: $10.7575 /$ aiac.abcmed.ca1.63

Published Date: February 2017

Peer-review is under responsibility of the 9th Iranian Stroke Congress.

Published by Australian International Academic Centre, Australia

This published work is open access under the CC BY license.

Available online at www.abcmed.aiac.org.au 